June 1998 • NREL/CP-510-24058

$$
\text { CONF- } 9711164--
$$

\title{
Progress Toward Achieving a Commercially Viable Solar Reflective Material
}

\author{
RECEIVED
}

JUN 261998

OSTI

C.E. Kennedy and R.V. Smilgys

DESTRISUTION OF THIS DOCUMENT IS UMUHMTED

\section{MASTER}

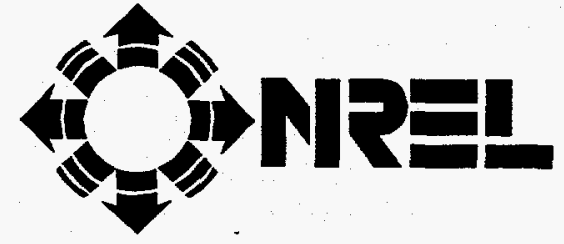

National Renewable Energy Laboratory 1617 Cole Boulevard Golden, Colorado 80401-3393

A national laboratory of the U.S. Department of Energy Managed by Midwest Research Institute for the U.S. Department of Energy under Contract No. DE-AC36-83CH10093 


\section{NOTICE}

This report was prepared as an account of work sponsored by an agency of the United States government. Neither the United States government nor any agency thereof, nor any of their employees, makes any warranty, express or implied, or assumes any legal liability or responsibility for the accuracy, completeness, or usefulness of any information, apparatus, product, or process disclosed, or represents that its use would not infringe privately owned rights. Reference herein to any specific commercial product, process, or service by trade name, trademark, manufacturer, or otherwise does not necessarily constitute or imply its endorsement, recommendation, or favoring by the United States govemment or any agency thereof. The views and opinions of authors expressed herein do not necessarily state or reflect those of the United States government or any agency thereof.

Available to DOE and DOE contractors from:

Office of Scientific and Technical Information (OSTI)

P.O. Box 62

Oak Ridge, TN 37831

Prices available by calling (423) 576-8401

Available to the public from:

National Technical Information Service (NTIS)

U.S. Department of Commerce

5285 Port Royal Road

Springfield, VA 22161

(703) $487-4650$ 


\section{DISCLAIMER}

Portions of this document may be illegible electronic image products. Images are produced from the best available original document. 
Progress Toward Achieving a Commercially Viable Solar Reflective Material

\author{
C. E. Kennedy and R. V. Smilgys \\ National Renewable Energy Laboratory, 1617 Cole Boulevard, M/S 1631, Golden, CO 80401 \\ Science Applications International Corporation, 1710 Goodridge Dr. M/S 2-3-1, \\ McLean, VA 22102
}

\begin{abstract}
Solar thermal technologies use large mirrors to concentrate sunlight for renewable power generation. The development of advanced reflector materials is important to the viability of electricity production by solar thermal energy systems. The reflector materials must be low in cost and maintain high specular reflectance for extended lifetimes under severe outdoor environments. Production processes associated with candidate materials must be scalable to mass production techniques. A promising low-cost construction uses a stainless steel foil substrate with a silver reflective layer protected by an optically transparent oxide topcoat. Thick ( 2 to 4 micron), dense alumina coatings provide durable protective layers. The excellent performance of alumina-coated reflector materials in outdoor and accelerated testing suggests that a larger field trial of the material is warranted. The key to producing a greater quantity of material for field deployment and testing without incurring substantial capital is the use of a chilled drum coater. An existing chamber is being modified, and the deposition rate will be increased prior to the installation of a drum coater to produce $1-\mathrm{ft}$ wide by $10-\mathrm{ft}$ long strips of solar reflector material. The production and performance of these materials are discussed.
\end{abstract}

\title{
1. INTRODUCTION
}

Solar thermal electric power systems use large solar reflectors to concentrate sunlight to generate electricity. The widespread application of solar thermal electric power generation depends on developing a durable, low-cost reflector. The goals for such a reflector are specular reflectance above $90 \%$ for at least 10 years under outdoor service conditions and a large-volume manufacturing cost of less than $\$ 10.80 / \mathrm{m}^{2}$ $\left(\$ 1.00 / \mathrm{ft}^{2}\right)(1)$. The National Renewable Energy Laboratory (NREL) is developing these materials for the U.S. Department of Energy (DOE) Concentrating Solar Power (CSP) Program. Currently, the best candidate materials for solar reflectors are silver-coated, low-iron glass, and silvered-polymer films. Polymer reflectors are lighter in weight, offer greater system design flexibility, and have the potential for lower cost than glass reflectors. These materials may meet the current reflector goal (2), but it is questionable whether they can meet a longer lifetime goal of 30 years of outdoor service.

Solar manufacturers are increasingly considering the use of thin $(<1.0 \mathrm{~mm})$ silvered glass as the reflector material for their concentrator designs. Thin-glass reflectors have several major advantages: excellent specular reflectance, projected long life, light weight (compared to thick glass), ability to be used on some curved configurations, and the general confidence of the solar manufacturing industry. However, thin glass has a number of disadvantages. It is expensive-ranging from $\sim \$ 1.50$ to $6.00 / \mathrm{ft}^{2}$, depending on cutting costs and quantity purchased. Thin glass is very fragile, both in shipping and handling and during the manufacturing and lifetime of the solar concentrator facet. The installation is labor intensive and not easily automated. There are indications that during weathering, thin-glass mirror constructions are susceptible to degradation in reflectance through interactions with the adhesives used to bond the mirror 
construction to substrate materials. In addition, cracking of thin glass mirrors during service and the propagation of corrosion from the cracks is a concern (3).

An alternate mirror construction for solar mirrors uses silvered polymers. Silver is the metal of choice in solar applications because of its high reflectivity. Protecting silver with a thin polymer (polymethylmethacrylate, [PMMA]) film is one way of making lightweight, flexible, solar mirrors. Data for PMMA demonstrates the following characteristics: excellent stability in the environment, excellent optical properties, ability to protect silver, and the ability to be extruded into a thin, flexible film (2). Silvered PMMA has several limitations, including relatively high cost, a lifetime less than 30 years, and poor adhesion between the silver and PMMA on exposure to water that can result in catastrophic delamination failure (4).

A promising low-cost "ultra-thin glass" reflector combining the best of both thin-glass and silvered-polymer reflectors consists of a silvered polymer protected by an optically transparent alumina top coating. The coating is deposited by ion-beam-assisted physical vapor deposition (IBAD). Ion-assisted deposition is critical to attaining dense, weatherable, protective coatings. In an ongoing project sponsored by NREL, Science Applications International Corporation (SAIC) of McLean, VA is developing a reflector that may meet the solar reflector lifetime goals. The material is a reflector that consists of a polymer substrate coated with a copper layer, followed by a layer of silver, and finally by a protective transparent inorganic top coating (Figure 1). Earlier, this basic design was recognized as having high potential, but the difficulty has been to find a durable top coating. Polyethylene terephthalate (PET) film was selected as the substrate material because of its low cost, good mechanical properties, and compatibility with silver or copper adhesion. The alumina top coating is essential to sustain high reflectance in outdoor service. Samples of this reflector have maintained high optical performance in accelerated testing for more than 3000 hours. The coating is deposited by IBAD (5). The alumina IBAD deposition rate, the coating thickness, and the desired annual production volume are the primary factors affecting the unit cost $\left(\$ / \mathrm{m}^{2}\right)$ of this reflector material. At 5- $\mu \mathrm{m}$ thickness, the deposition rate must exceed $60 \mathrm{~nm} / \mathrm{s}$ to operate a single roll coater at maximum capacity, while at $1-\mu \mathrm{m}$ thickness, rates as low as $20 \mathrm{~nm} / \mathrm{s}$ can still be accommodated by a single roll coater (6). Solar reflectors produced using this technique may represent an opportunity to bring solar power generation to reality.

If the alumina-coated reflector were supplied on a stainless steel web, the cost to solar thermal system manufacturers of a thin-glass heliostat facet could be reduced $25 \%$ to $40 \%$. The cost reduction would be primarily from the reduction in labor costs. One approach is to produce the reflector on a polymer web, then laminate the processed polymer web to a steel web. Concerns exist that lamination may damage the relatively brittle alumina coating; a better approach is to produce the reflector directly on a steel web. Three limitations must be overcome before this will be feasible. First, the steel web surface must be made specular prior to metallization. This may be achieved either by prelamination with a polymer web or by application of a polymeric leveling layer. Second, a means must be provided to prevent damage to the substrate and preceding layers during high deposition rates. One way to achieve this is to cool the substrate during deposition. A steel web will have a poorer heat transfer rate into a cooled stage than a polymer web of the same thickness. This is because polymer webs transfer heat through the outgassed layer on the back of the web, which is lacking at the back of the steel web. Custom stage designs are being investigated that would inject gas between the steel web and cooled stage to improve thermal conduction. Third, the means of attaching the alumina-coated stainless steel reflector to the facet without damaging the reflector needs to be determined.

The optical performance and durability of silvered PET protected by an alumina top coating $0.5-$ $\mu \mathrm{m}$ to $4-\mu \mathrm{m}$ thick is discussed. The durability achieved by the reflector thus far is promising. 


\section{EXPERIMENTAL}

Solar reflector material samples were produced in a laboratory chamber equipped for electronbeam evaporation and ion-beam bombardment; details of the process have been reported (6). Samples were produced with an alumina evaporation rate of $1 \mathrm{~nm} / \mathrm{s}$ limited by equipment constraints and the inability to cool the substrate. The deposition techniques used were dictated by the batch equipment available and are not cost-effective procedures for large-volume production. Utilizing large-volume production techniques would increase the deposition rate and lower the cost.

The hemispherical reflectance of the samples was measured using a Perkin-Elmer Lambda 9 UVVIS-NIR spectrophotometer with a $60-\mathrm{mm}$ integrating-sphere attachment. The solar-weighted (air-mass 1.5) hemispherical reflectance was calculated from data collected in the 250- to 2500-nm range. Such measurements are accurate to $\pm 0.5 \%$. The absolute specular reflectance was measured as a function of acceptance angle using a reflectometer developed at NREL (7). The measurements were made at 4, 8, 12, 18 , and 25 -mrad full-cone angles at $650 \mathrm{~nm}$ on membrane samples stretched under tension.

The durability of the solar reflector material was monitored during testing under real-time outdoor exposure and by accelerated exposure. Outdoor exposure was performed in Golden, Colorado, one of seven outdoor test sites operated by NREL and equipped with meteorological monitoring instruments. Accelerated testing was performed in an Atlas Weather-Ometer (WOM), an Atlas Hereaus XENO 1200 LM (XENO), and a 1000-W Oriel Solar Simulator. The WOM, XENO, and Solar Simulator allow control of exposure temperature and ambient humidity. They use a xenon-arc light source with filters designed to closely match the terrestrial air-mass 1.5 solar spectrum. The WOM operates continuously at $60^{\circ} \mathrm{C}$ and $80 \%$ relative humidity (RH), with light levels about equal to one sun outdoor exposure. A single day of testing (24 hours) is roughly equivalent to three times the outdoor exposure in terms of cumulative light dose. The XENO operates continuously at $60^{\circ} \mathrm{C}$ and $80 \% \mathrm{RH}$, with light levels about twice that of the WOM. The Solar Simulator operates at $80^{\circ} \mathrm{C}$ and $80 \% \mathrm{RH}$ and can achieve intensities of 30 to 50 times the outdoor exposure in a wavelength band between 300 and $500 \mathrm{~nm}$. The spectral intensity distributions of the various light sources in the accelerated exposure chambers were verified using a spectral radiometer system.

\section{RESULTS}

The deposition structure of samples tested is identified in Table I. As produced, with appropriate selection of deposition parameters, the alumina was visually free of cracks and showed excellent adhesion to the silver by the ASTM D 3359-78 tape test. Scanning electron microscopy previously showed a dense microstructure of the IBAD alumina (6).

The spectral hemispherical reflectance for a typical alumina coated reflector is compared with a thin-glass reflector in Figure 2. The solar-weighted (air-mass 1.5) hemispherical reflectance is about $96 \%$. The initial specular reflectance within an 8-mrad full-cone angle is typically about $91 \%$.

Figure 3 shows the optical durability of samples exposed in the solar simulator chamber. All of the samples from 0.5 - to 5.2- $\mu \mathrm{m}$-thick alumina sustained up to 1800 hours of exposure without degradation of the solar-weighted hemispherical reflectance. For some samples, exposure continued up to 3500 hours with little to no loss of reflectance. No significant difference in optical durability could be discerned between samples with an alumina coating between 0.5 - and $5-\mu \mathrm{m}$ thick. This is the longest successful solar simulator exposure time for a polymer-based reflector tested at NREL to date.

Reflectors under exposure in Colorado for 29 months with the thicker alumina coatings ( $>4 \mu \mathrm{m}$ ) maintain their initial hemispherical reflectance (Figure 4) within $2 \%$. The thinner alumina coatings show a 
significant loss of about $30 \%$, typically caused by delamination of the alumina coating. After 18 months of outdoor exposure, visually more of the $0.5-\mu \mathrm{m}$ alumina coating than the $1-\mu \mathrm{m}$ alumina is adhered to the reflector, causing the $0.5-\mu \mathrm{m}$ alumina to outperform the $1-\mu \mathrm{m}$ alumina reflectors. Samples exposed in the WOM for 24 months (Figure 5) and in the XENO for 13 months (Figure 6) follow the same trend where the thicker alumina coatings are more durable. This is in agreement with SAIC's results that thick alumina coatings exposed to acid vapor are able to withstand degradation for a longer period of time than samples with thin alumina coatings. Experiments also show that the thinner alumina coatings $(<2 \mu \mathrm{m})$ are more sensitive to stress, resulting in reflectance losses caused by changes in the deposition conditions (Figure 7). The alumina coating can have a residual stress that causes flexible substrates to curl. Compressive stress causes the alumina side to curl inwards, while tensile stress causes the PET side to curl inwards. Table II identifies the deposition structure in relation to the deposition conditions (ion current density, mounting condition), and resulting stress conditions experienced by several sample constructions. In flex mounting, the PET substrate was held under tension over a curved surface, and the PET is lying flat on the planetary in flat mounting. The symbols ' - ', ' 0 ', and ' + ' are used qualitatively to describe tensile, neutral, and compressive stress, respectively. The changes in ion current density, ion bombardment gas mixture, and sample mounting conditions may lead to higher levels of residual compressive stress in the alumina coatings, causing cracking and delamination of the alumina coating.

The 3-mil stainless steel, used in heliostat facets, is very non-specular. Reflectors made by directly depositing alumina onto silvered stainless steel would also be very non-specular. Adding a layer to level the stainless steel requires that layer to be specular and to electrically isolate the silver from the stainless steel to prevent galvanic corrosion in the presence of water. In an effort to improve the specularity of thin stainless steel, samples were leveled with a variety of organic coatings or laminated with PET. The leveled stainless steel samples were coated with $100-\mathrm{nm}$ silver and then measured with the reflectometer. Adding organic coatings to the stainless steel somewhat improved the specularity (Figure 8). Only laminating 3-mil PET to stainless steel foil improved the specular reflectance of the construction to above $90 \%$ from 4 - to 25 -mrad full-cone angle. Figure 9 shows the optical durability of reflectors

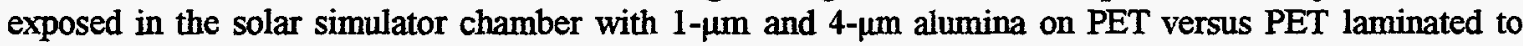
stainless steel foil and then coated with the reflector coatings. Both were laminated to aluminum substrates after deposition. All of the samples sustained up to 2000 hours of exposure with little degradation, and then the 1- $\mu \mathrm{m}$ alumina coatings began to degrade. The comparable 1- $\mu \mathrm{m}$ alumina samples exposed in the WOM and outdoors for up to 15 months show some loss in hemispherical reflectance, whereas the 4- $\mu \mathrm{m}$ alumina samples have not begun to degrade.

\section{FUTURE WORK}

The quality of the alumina coating and the corresponding performance of the mirror is very process dependent. A large vacuum chamber at SAIC (McLean, VA) has been brought on-line to continue the initial development work and for the intended next step toward the demonstration of commercial potential, namely, increased rate of alumina deposition. The system at SAIC has several advantages including larger sample size, greater throughput, and significantly greater scalability of the coating process parameters. Key components of the deposition system already in place include an 11,000 liter vacuum chamber (cylinder $7 \mathrm{ft}$ in diameter and $12 \mathrm{ft}$ long) pumped by a $3000 \mathrm{l} / \mathrm{s}$ cryopump, a four pocket electron beam evaporator with a $14 \mathrm{~kW}$ power supply, and a $16-\mathrm{cm}$ gridded ion source. Upgrades under way include the installation of two additional cryopumps and a 30-kW evaporator power supply.

Three principal factors limit the deposition rate: alumina evaporation rate, ion-beam assist, and substrate cooling. We project that with the existing evaporator and ion source, a deposition rate of at least $3 \mathrm{~nm} / \mathrm{s}$ over a $1-\mathrm{ft}^{2}$ sample, or $15 \mathrm{~nm} / \mathrm{s}$ over a 6 -in ${ }^{2}$ sample can be reached. For a deposition rate in excess of a few nanometers per second, temperature-sensitive substrates must be actively cooled. In the next phase of development, we plan to construct a water-cooled flat stage that will hold a sheet of PET 8 in. 
wide by 24 in. long for coating. In operation, the stage will be moved through the deposition zone by a linear reciprocating motion. A flat stage was chosen instead of a drum coater to reduce cost.

The excellent performance of alumina-coated reflector material in outdoor and accelerated testing suggests that larger field trials of the alumina-coated reflector are warranted. If the reflector continues to show excellent performance after increasing the deposition rate, over $70-\mathrm{ft}^{2}$ of alumina-coated reflector material on leveled stainless steel foil will be produced for fabrication into a full-scale facet in a solar thermal system.

The key to greatly increasing reflector production without incurring the expense of a roll coater is the use of a drum coater. A drum only $3 \mathrm{ft}$ in diameter and $1 \mathrm{ft}$ wide can hold a strip of leveled stainless steel foil (or PET film) nearly $10 \mathrm{ft}^{2}$ in area. A drum of this size will easily fit in the 7 - $\mathrm{ft}$ diameter SAIC chamber. With active cooling through the use of a flowing coolant, a deposition rate up to $5 \mathrm{~nm} / \mathrm{s}$ or more should be possible. A useful feature of a drum coater is that it can be operated in a fashion similar to either a roll coater or a planetary coater. When the full thickness of alumina coating is deposited during a single rotation of the drum, the coating is deposited in one pass. This is identical to deposition in a roll coater. If, instead, the drum is rotated many times during deposition, the coating is deposited in layers. This is identical to deposition in a planetary coater. Because of this dual capability, a drum coating represents a cost-effective and technically important research step toward roll coating. SAIC's large chamber with a drum coater will allow high-rate development work and sufficient reflector material can be produced to perform meaningful field trials.

A new multi-process vacuum deposition system designed and built by Pernicka Corporation of Fort Collins, CO was completed and delivered to NREL in September 1997. The schematic is shown in Figure 10. The new deposition system provides the capability to deposit films of metals, conductors, oxides, and insulators by evaporating and sputtering to form multilayered optical structures of the type used with solar systems (e.g., anti-reflective coating, mirrors, lenses, absorbers, light pipes, and solid state devices). The system can evaporate sequentially or co-deposit by e-beam. An ion beam gun allows IBAD to be used to improve the quality, composition, and density of the material. Reactive magnetron sputtering by $\mathrm{DC}$ and pulsed-DC can deposit a large variety of oxides and metals at relatively high rates. The deposition system will be used for research and development of a wide variety of thin-film devices and coatings in support of DOE's CSP program.

The new deposition system at NREL will allow the exploration of other dense transparent protective oxide coatings and multilayer coatings. Other oxide coatings have intrinsically faster deposition rates and desirable mechanical properties. The use of oxide interlayers can improve adhesion between optically desirable materials (4). By tailoring the protective oxide layer and using optically clear interlayers, the performance of the "ultra-thin glass" reflectors could be improved.

\section{CONCLUSION}

Silvered-PET protected by IBAD deposited alumina represents an advancement in solar reflector durability. Preliminary results have shown an initial solar-weighted hemispherical reflectance of $95 \%$ and excellent optical durability in both accelerated and outdoor (Colorado) exposure testing. Additional issues to address include determining the minimum coating thickness needed to ensure optical durability, increasing the deposition rate, testing the long-term mechanical stability of the material under biaxial stress, and field testing the material. Research into a better stainless steel leveling layer is being pursued. The alumina-coated reflector material under development offers promise as a commercially viable solar reflector material. The deposition system at SAIC is large enough and has sufficient capability to support a range of preproduction scale coatings work and the new state-of-the-art deposition system at NREL will allow the development of additional innovative coatings to be prototyped. 


\section{ACKNOWLEDGMENTS}

C. E. K. thanks J. C. Pernicka and the staff at Pernicka Corporation for designing and building the deposition system and acknowledges R. Goggin, G. Jorgensen, and D. King from NREL. R. V. S. thanks D. M. Althouse for excellent technical work, and J. A. Isaacs for the cost analysis. We acknowledge J.S. Ross, D. J. Kester, T. P. Medill, and R. A. Hallman at Armstrong World Industries for initial development and invaluable assistance in the course of this work.

This work was partially supported by the U.S. Department of Energy under Contract No. DE-AC36-83CH10093.

\section{REFERENCES}

(1) U.S. Department of Energy, National Solar Thermal Technology Program, Five-Year Research and Development Plan, 1986-1990, DOE/CE-0160, Sept. 1986.

(2) P. Schissel, G. Jorgensen, C. Kennedy, and R. Goggin, Sol. Energy Mater., 33 (1994) 183.

(3) C. Kennedy, NREL Internal Milestone Report: Preliminary Results of Optical Durability Testing of Candidate Thin Glass Solar Mirror Constructions, March 1997.

(4) P. Schissel, C. Kennedy, and R. Goggin, J. Adh. Sci. Tech., 9 (1995) 413.

(5) R. V. Smilgys, J. A. Isaacs, and C. E. Kennedy, Proc. 10 Inter. Conf. Vacuum Web Coating, (1996) 234.

(6) C. E. Kennedy, R. V. Smilgys, D. A. Kirkpatrick, and J. S. Ross, Thin Solid Films, 304 (1997) 305.

(7) I. Susemihl and P. Schissel, Sol. Energy Mater., 16 (1987) 403. 


\begin{tabular}{|c|c|}
\hline \multicolumn{2}{|c|}{$\begin{array}{l}\text { Table I. Deposition Structure of Sample Constructions Tested } \\
\text { ( } 1 \mathrm{~nm} / \mathrm{s} \text { deposition rate) }\end{array}$} \\
\hline Construction & Deposition Structure \\
\hline A & $\mathrm{Al}_{2} \mathrm{O}_{3}(5.2 \mu \mathrm{m}) / \mathrm{Ag}(70 \mathrm{~nm}) / \mathrm{Cu}(40 \mathrm{~nm}) / \mathrm{PET}$ \\
\hline B & $\mathrm{Al}_{2} \mathrm{O}_{3}(4 \mu \mathrm{m}) / \mathrm{Ag}(70 \mathrm{~nm}) / \mathrm{Cu}(40 \mathrm{~nm}) /$ PET or stainless steel \\
\hline $\mathrm{C}$ & $\mathrm{Al}_{2} \mathrm{O}_{3}(4 \mu \mathrm{m}) / \mathrm{Ag}(100 \mathrm{~nm}) / \mathrm{Cu}(50 \mathrm{~nm}) / \mathrm{PET}$ or $[1$ or $3 \mathrm{mil} \mathrm{PET} / \mathrm{stainless}$ steel] \\
\hline D & $\mathrm{Al}_{2} \mathrm{O}_{3}(2 \mu \mathrm{m}) / \mathrm{Ag}(70 \mathrm{~nm}) / \mathrm{Cu}(40 \mathrm{~nm}) / \mathrm{PET}$ \\
\hline $\mathrm{E}$ & $\begin{array}{l}\mathrm{Al}_{2} \mathrm{O}_{3}(2 \mu \mathrm{m}) / \mathrm{Ag}(100 \mathrm{~nm}) / \mathrm{Cu}(50 \mathrm{~nm}) / \mathrm{PET} \\
\text { [also deposited under }-, 0,+ \text { stress conditions] }\end{array}$ \\
\hline F & $\mathrm{Al}_{2} \mathrm{O}_{3}(1.5 \mu \mathrm{m}) / \mathrm{Ag}(200 \mathrm{~nm}) / \mathrm{Cu}(50 \mathrm{~nm}) / \mathrm{PET}$ \\
\hline G & $\mathrm{Al}_{2} \mathrm{O}_{3}(1 \mu \mathrm{m}) / \mathrm{Ag}(100 \mathrm{~nm}) / \mathrm{Cu}(50 \mathrm{~nm}) / \mathrm{PET}$ \\
\hline $\mathbf{H}$ & $\begin{array}{c}\mathrm{Al}_{2} \mathrm{O}_{3}(1 \mu \mathrm{m}) / \mathrm{Ag}(100 \mathrm{~nm}) / \mathrm{Cu}(50 \mathrm{~nm}) / \mathrm{PET} \text { or }[1 \text { or } 3 \mathrm{mil} \text { PET/stainless steel] } \\
\text { [also deposited under } 0,+,+ \text { stress conditions] }\end{array}$ \\
\hline I & $\mathrm{Al}_{2} \mathrm{O}_{3}(0.5 \mu \mathrm{m}) / \mathrm{Ag}(100 \mathrm{~nm}) / \mathrm{Cu}(50 \mathrm{~nm}) / \mathrm{PET}$ \\
\hline $\mathrm{J}$ & $\mathrm{Al}_{2} \mathrm{O}_{3}(0.25 \mu \mathrm{m}) / \mathrm{Ag}(100 \mathrm{~nm}) / \mathrm{Cu}(50 \mathrm{~nm}) / \mathrm{PET}$ \\
\hline
\end{tabular}

\begin{tabular}{|c|c|c|c|}
\hline \multicolumn{4}{|c|}{$\begin{array}{c}\text { Table II. Residual Stress of Alumina and Deposition } \\
\text { Conditions of Sample Constructions Tested }\end{array}$} \\
\hline \multirow{3}{*}{ Construction } & Stress & Ion Current & Mounting \\
\hline & - & 540 & Flex \\
\cline { 2 - 4 } & 0 & 460 & Flex \\
\cline { 2 - 4 } & + & 600 & Flex \\
\hline \multirow{3}{*}{ H } & 0 & 600 & Flat \\
\cline { 2 - 4 } & + & 540 & Flex \\
\cline { 2 - 4 } & ++ & 600 & Flex \\
\hline
\end{tabular}




\section{Top Protective Layer (0.5 - $\left.4 \mu \mathrm{m} \mathrm{Al}_{2} \mathrm{O}_{3}\right)$}

\section{Reflective Layer (1000 A Ag)}

\section{Metal Back Layer (700 A Cu)}

\section{Substrate (PET)}

(Leveling Layer)

(3 mil Stainless Steel)

Figure 1. Advanced solar reflector material structure. Alumina protective layer, silver reflective layer, copper back-protective layer on PET substrate or leveled 3 mil stainless steel foil.

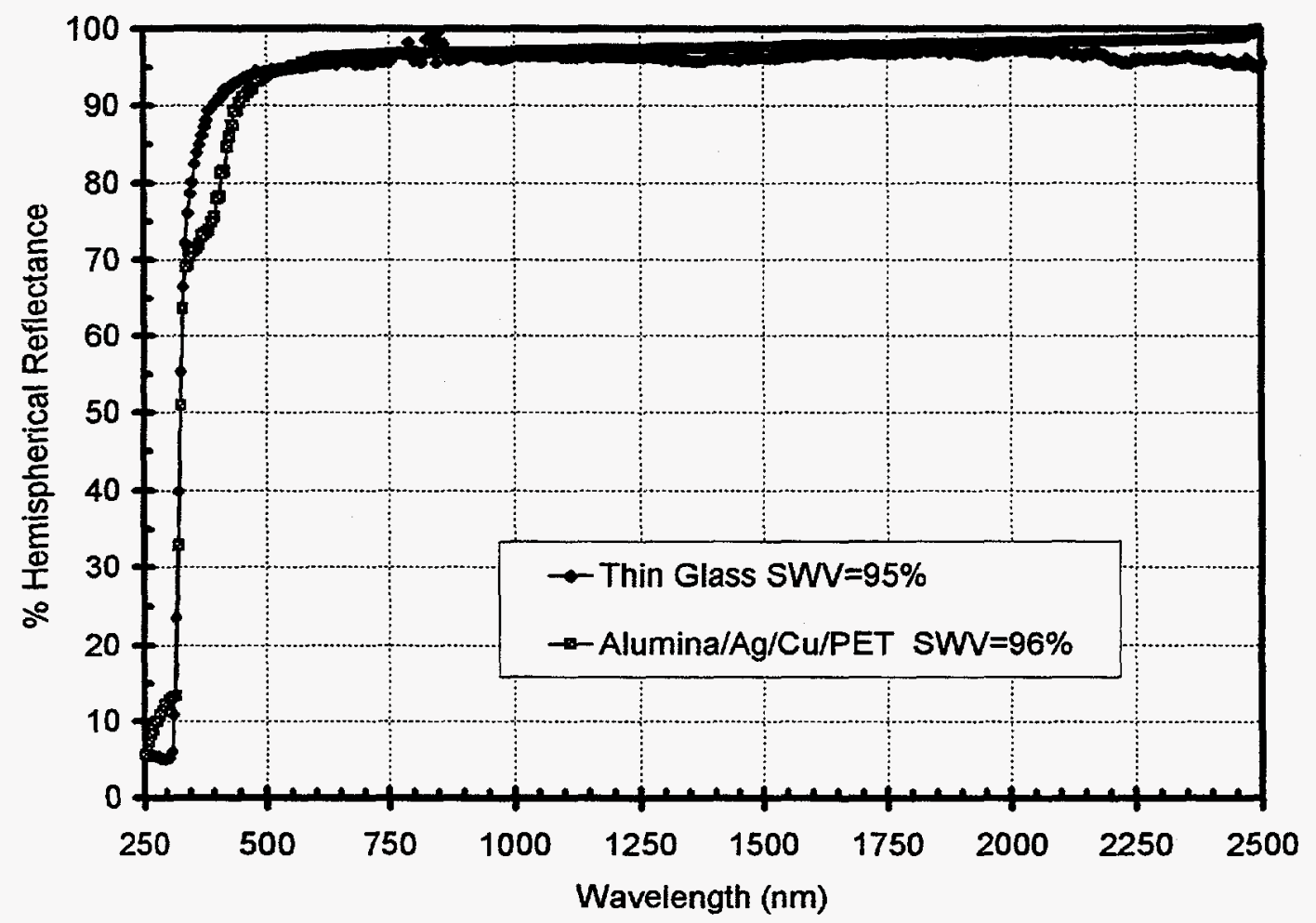

Figure 2. Typical hemispherical reflectance spectrum for an alumina-protected silver reflector with a solar-weighted (air-mass 1.5 ) value (SWV) of $\sim 96 \%$. Typical hemispherical reflectance spectrum for a silvered thin glass $(<1.0 \mathrm{~mm})$ reflector with a solar-weighted value of $\sim 95 \%$. 


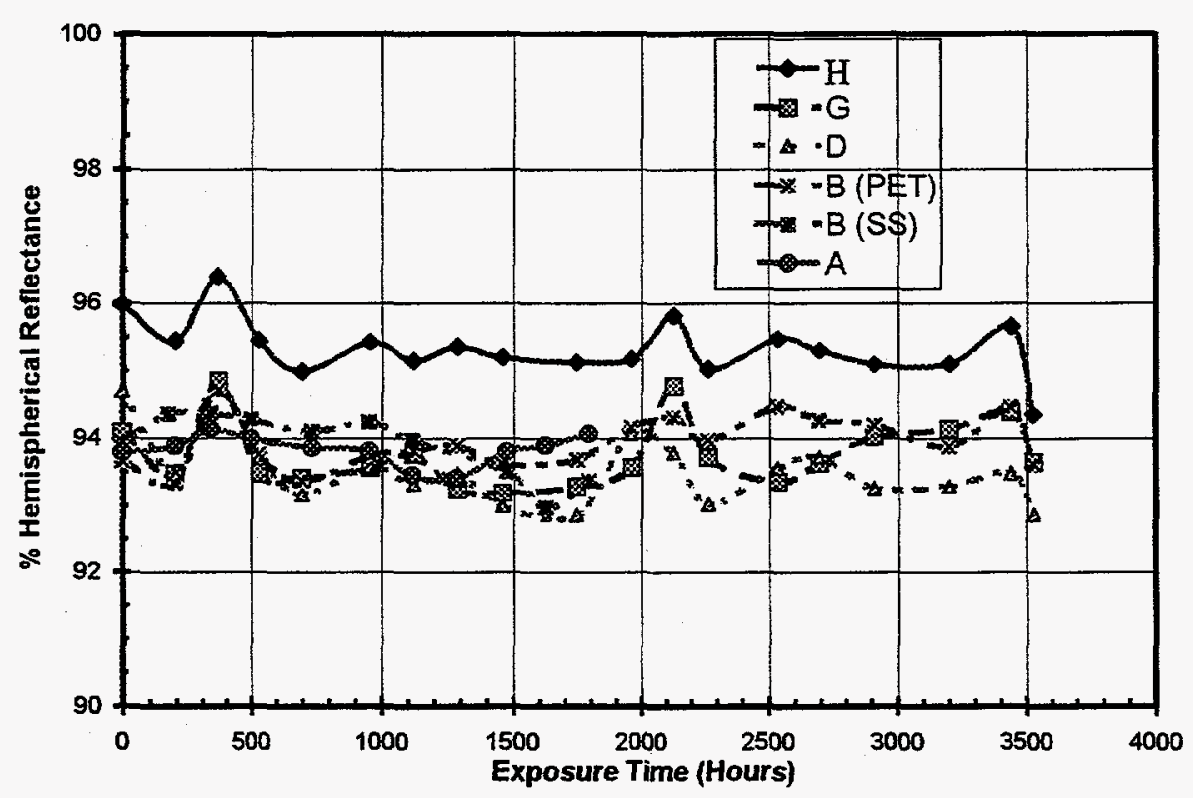

Figure 3. Solar-weighted (air-mass 1.5) hemispherical reflectance (\%) of alumina-coated reflectors with the alumina thickness between 0.5 to $5.2 \mu \mathrm{m}$ versus time of exposure in solar simulator.

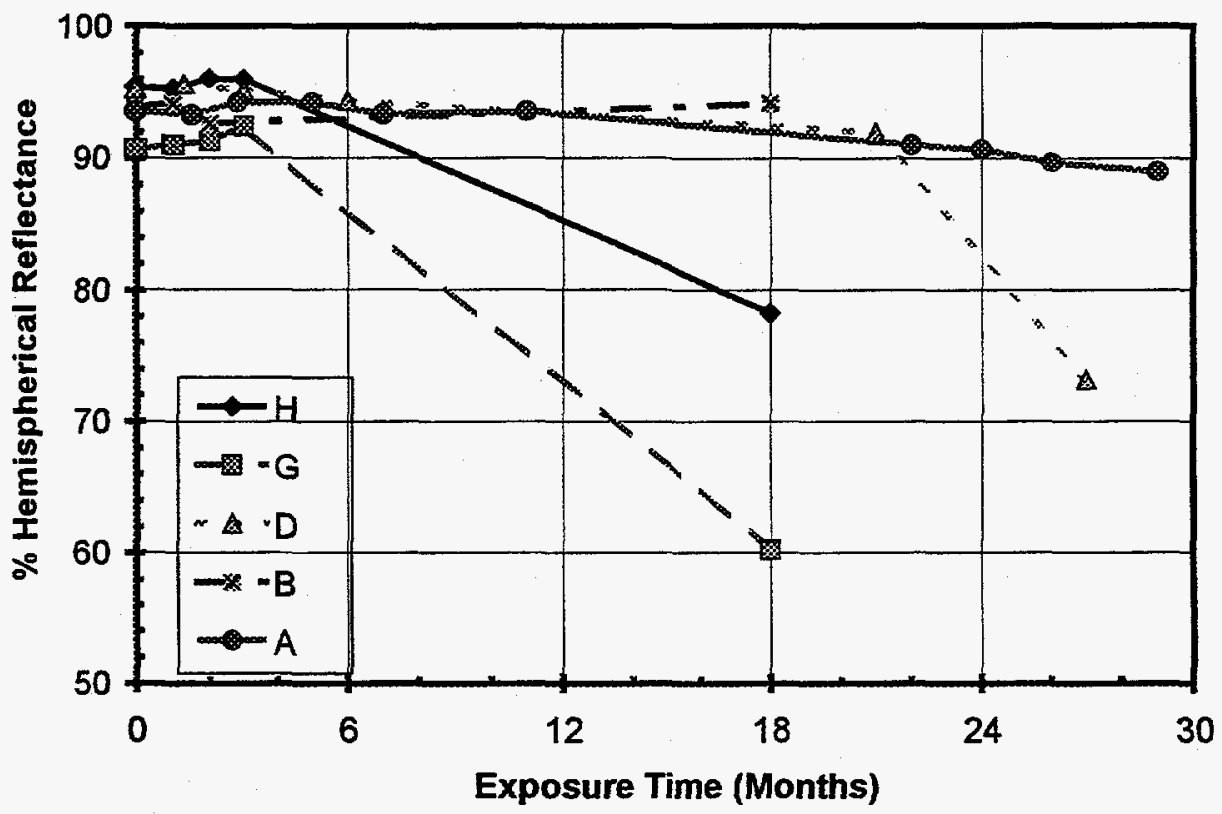

Figure 4. Solar-weighted (air-mass 1.5) hemispherical reflectance (\%) of alumina-coated reflectors on PET substrates with the alumina thickness between 0.5 and $5.2 \mu \mathrm{m}$ versus time of exposure outdoors in Colorado. 


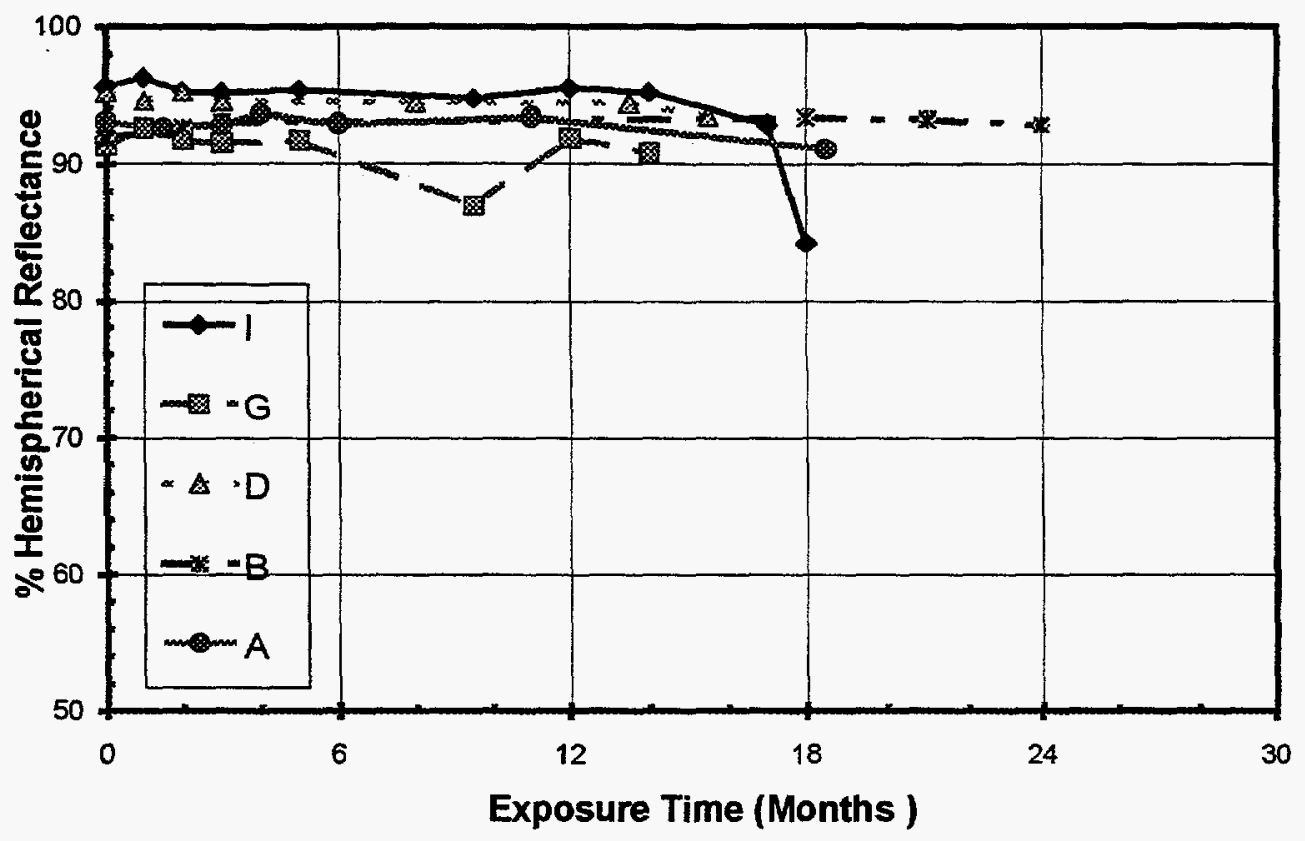

Figure 5. Solar-weighted (air-mass 1.5) hemispherical reflectance (\%) of alumina-coated reflectors on PET substrates with the alumina thickness between 0.5 and $5.2 \mu \mathrm{m}$ versus time of exposure in the WOM.

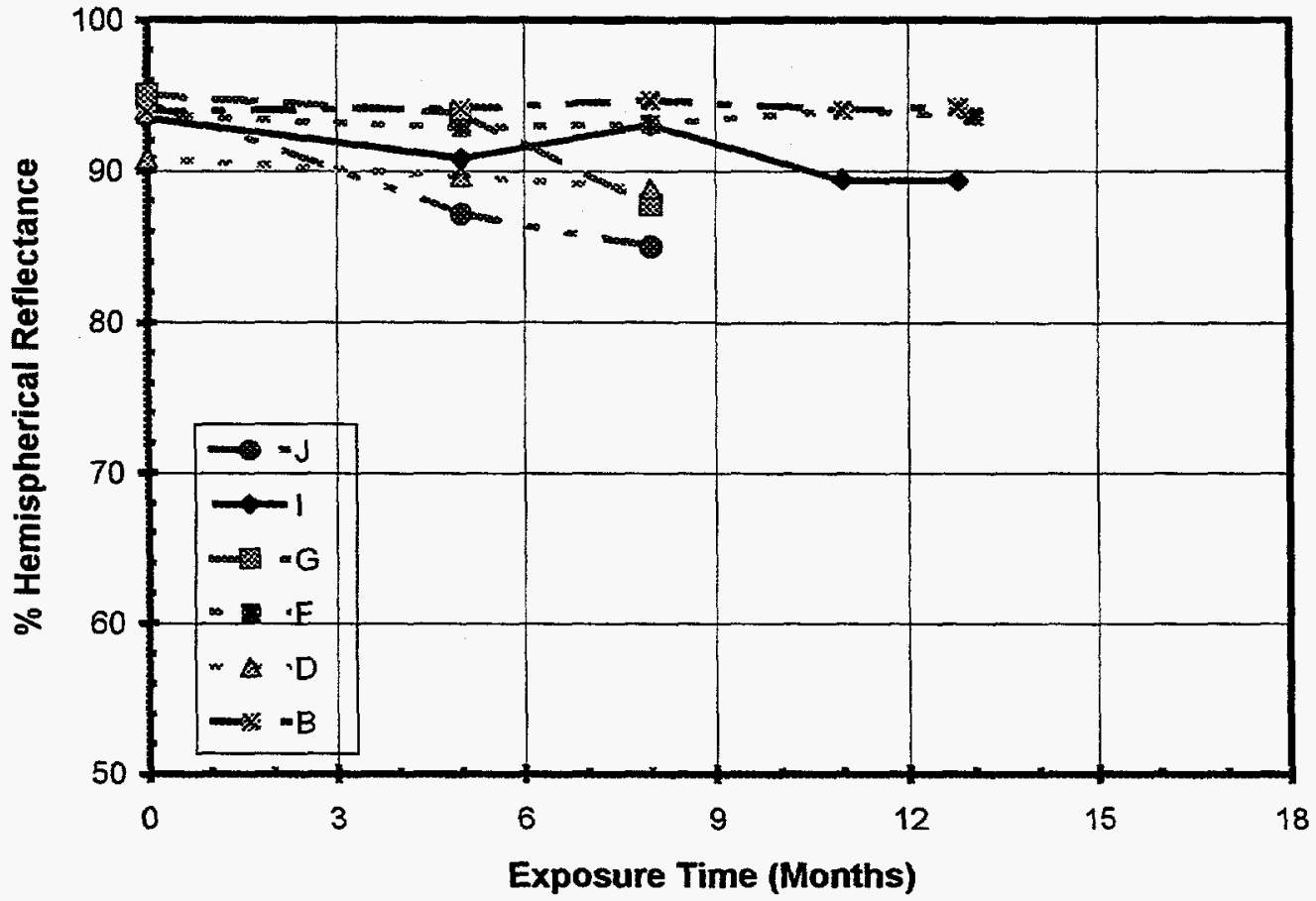

Figure 6. Solar-weighted (air-mass 1.5) hemispherical reflectance (\%) of alumina-coated reflectors on PET substrates with the alumina thickness between 0.25 and $4 \mu \mathrm{m}$ versus time of exposure in the XENO. 


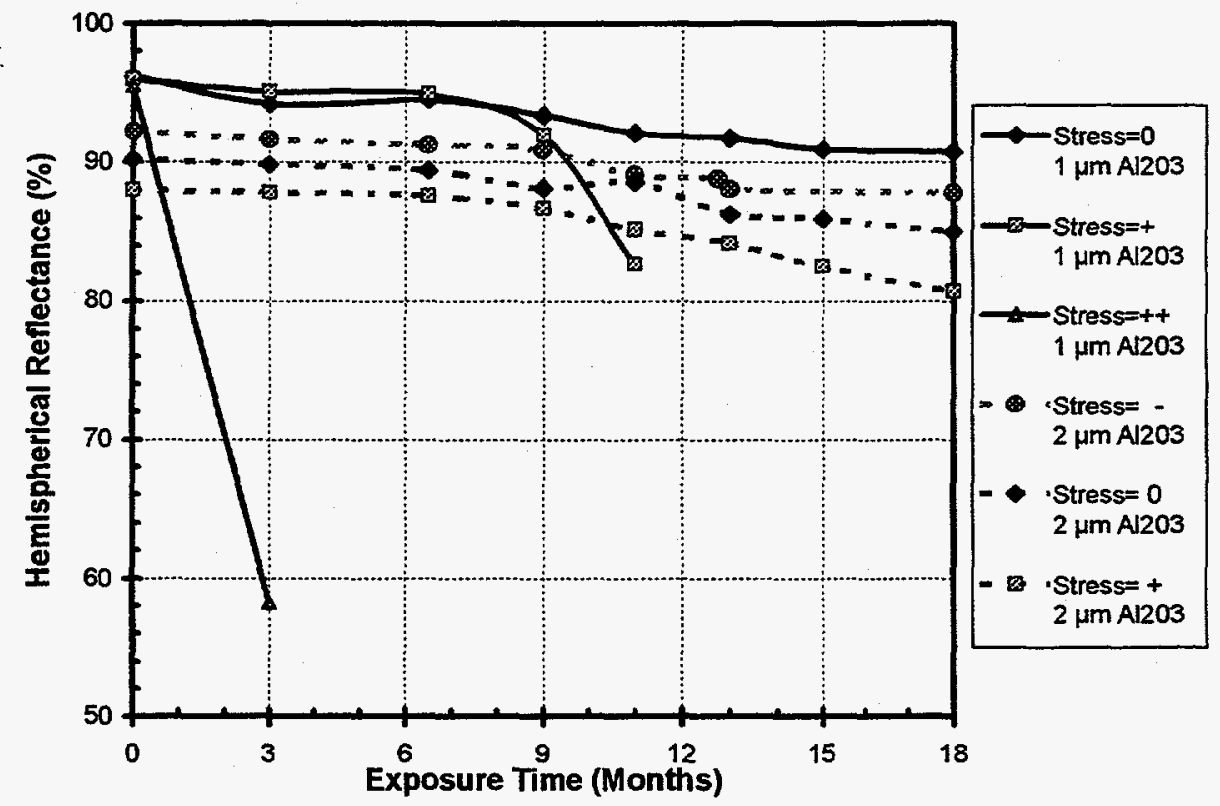

Figure 7. Solar-weighted (air-mass 1.5) hemispherical reflectance (\%) of 1 and $2 \mu \mathrm{m}$ alumina-coated reflectors on PET substrates deposited under various stress conditions by changing ion beam current densities, gas mixtures, and substrate mounting conditions versus time of exposure outdoors in Colorado (in months). The symbols ' - ', ' 0 ', ' + ', and ' ++ ' are used qualitatively to describe tensile, neutral, compressive, and very compressive stress, respectively.
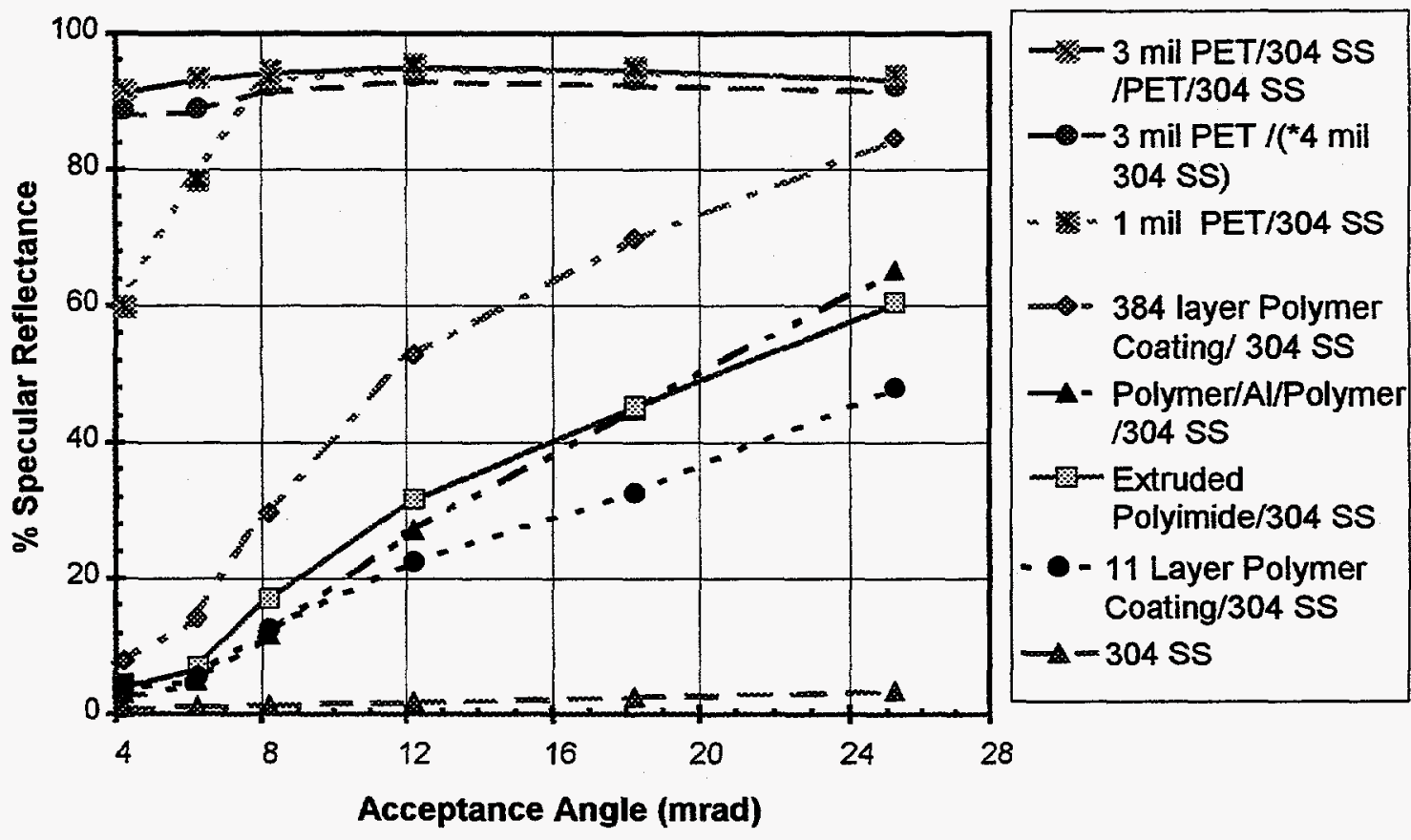

Figure 8. Specular reflectance (\%) of silvered $(100 \mathrm{~nm})$ unlevelized thin stainless steel foil $(3 \mathrm{mil}$ except for sample labeled $4 \mathrm{mil}$ ) and stainless steel leveled with a variety of organic coatings and laminated PET versus acceptance angle (in mrad). 


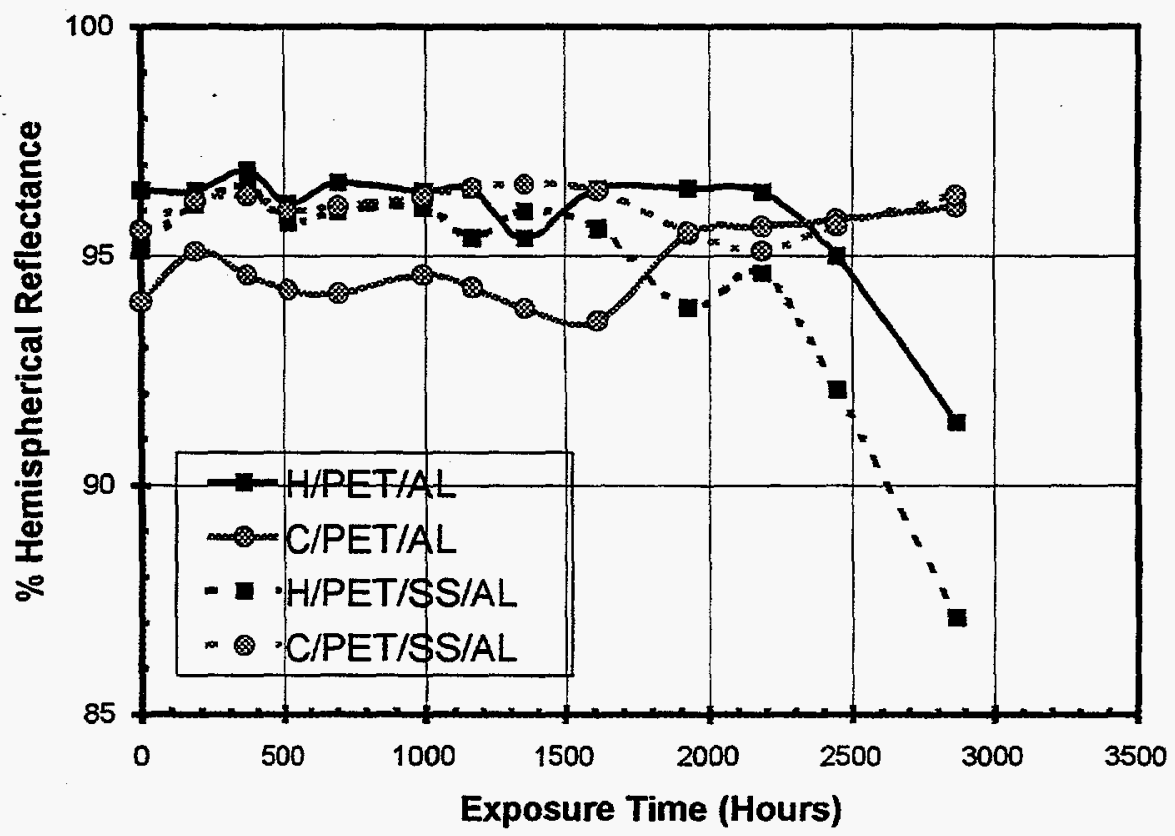

Figure 9. Solar-weighted (air-mass 1.5) hemispherical reflectance (\%) of 1- $\mu \mathrm{m}$ and 4- $\mu \mathrm{m}$ aluminacoated reflectors on PET (post deposition laminated to aluminum substrates) and stainless steel foil leveled with PET substrates versus time of exposure in the solar simulator.

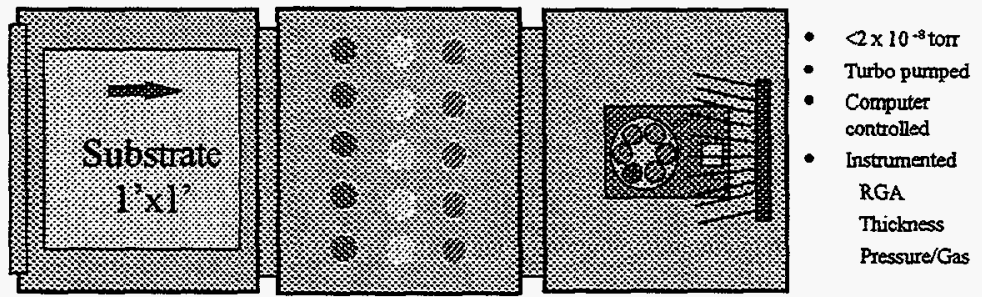

\footnotetext{
- Load-Lock Chamber - Sputtering Chamber - E-Beam Chamber

- l'xl' cooled or heated Substrate (polymer, glass, metal)

- Future PECVD

- Future Web
}

Figure 10. Top-view schematic of NREL's Multi-Process Vacuum Deposition System built by Pernicka Corp. of Fort Collins, CO. 